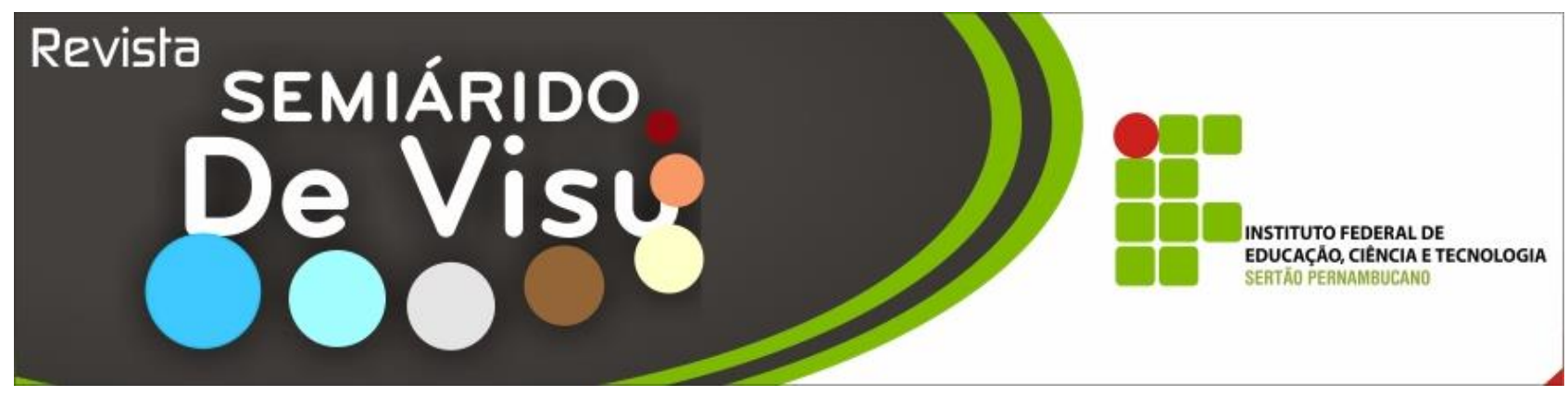

\title{
Convivência com o Semiárido: a ameaça da escassez da palma forrageira (Opuntia ficus-indica) frente aos processos produtivos de camponeses do Cariri Paraibano
}

\author{
Luana Patrícia Costa Silva ${ }^{1}$, Alexandre Eduardo de Araújo ${ }^{2}$, Daniel Duarte pereira ${ }^{3}$, \\ Albertina Maria Ribeiro Brito de Araújo ${ }^{4}$ \\ 1,2,3,4 Universidade Federal da Paraíba, Centro de Ciências Humanas, Sociais e Agrárias. Campus III, \\ Cidade Universitária, Bananeiras - PB, CEP: 58.200-000. Telefone: 3363-1200/ E-mail: \\ ${ }^{1}$ luana_gca@hotmail.com; ${ }^{2}$ alexandreeduardodearaujo@ hotmail.com; ${ }^{3}$ danielduartepereira@ hotmail.com; \\ 4albertinari@hotmail.com
}

\begin{abstract}
RESUMO: As estiagens vêm assolando os camponeses no cariri paraibano, isso acontece com maior ênfase por uma maior deficiência hídrica, característica da região. A pecuária, principal atividade da região, possui como base forrageira a palma, cactácea que se adaptou muito bem a nossa realidade hídrica. Desta forma o principal objetivo desse trabalho é de analisar os aspectos ligados aos fatores e processos produtivos de tal forrageira e como sua escassez está sendo sentida pelos camponeses. Consideramos esta pesquisa de cunho qualitativo, à medida que nos utilizamos de ferramentas como a pesquisa participativa e as entrevistas semi-estruturadas. Identificamos que a palma aparece realmente como forrageira de base para os camponeses e vem causando decadência na produção, afetando principalmente a base econômica das famílias, ainda, destacamos a rentabilidade de quem tem a palma nos períodos de estiagem. Consideramos que se faz necessário estratégias sustentáveis que subsidiem a preparação para os longos períodos de estiagem, principalmente na preservação das bases alimentares dos rebanhos, que se configura no cariri como principal atividade econômica.
\end{abstract}

Palavras-chave: Suporte forrageiro, processos sustentáveis, atividade econômica.

\section{Living with the Semi-Arid: the threat of the scarcity of forage palm (Opuntia ficus- indica) to the productive processes of peasants from Paraíba}

\begin{abstract}
The droughts have been plaguing the peasants in the caribbean of Paraiba, this happens with greater emphasis by a greater water deficiency, characteristic of the region. Livestock, the main activity of the region, has as a base forage the palm, cactus that has adapted very well to our water reality. In this way the main objective of this work is to analyze theaspects related to the factors and productive processes of such forage and how its scarcity is felt by the peasants. We consider this qualitative research, as we use tools such as participatory research and semi-structured interviews. We identified that the palm actually appears as a basic fodder for the peasants and has been causing decay in production, affecting mainly the economic base of the families, we also highlight the profitability of those who have the palm during the dry season. We consider that sustainable strategies are necessary to subsidize the preparation for the long periods of drought, mainly in the preservation of the food bases of the herds, which is configured in the cariri as main economic activity.
\end{abstract}

Keywords: Forage support, sustaina bleway, economic activity. 
Introdução

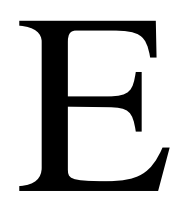
stiagens, Secas, Secas Verdes, Retiradas, Perdas não são termos estranhos ao cotidiano de quem vive nos Cariris Paraibanos (Ocidental e Oriental) - um dos Polos Xéricos do Brasil. Exceto a Estiagem que é um fenômeno natural, todos os outros termos estão ligados ao processo de ocupação da região que tem como datação cartorial uma sesmaria requerida no ano de 1665 (ALMEIDA, 1962), mas já citando atividades pecuaristas desde 1663, a partir do atual município de Boqueirão no Cariri Oriental. Ocupação está sempre pautada na apropriação dos recursos ambientais existentes, de forma nem sempre ordenada e sustentável.

Posteriormente, uma sesmaria requerida nos atuais domínios dos municípios de Ouro Velho e Prata no Cariri Ocidental no ano de 1699 corrobora a ocupação pela atividade pecuária sempre baseada na pecuária extensiva fragilizada pelas estiagens e secas recorrentes. Mais especificamente na área atual do Assentamento Zé Marcolino, novos pedidos de sesmarias nos anos de 1722 e 1740 referendam tanto a atividade pecuária como a gênese latifundiária da região (PEREIRA, 2008).

Das sesmarias, surgiram as Fazendas e das sobras de terras entre as sesmarias (travessões) surgiram muitos sítios e comunidades rurais. Estas por sua vez também advieram das sucessivas divisões das fazendas por heranças, compras, trocas, posses e usucapiões. Cotidianamente a região se apresenta como área de atuação de reforma agrária representada em nível estadual pelo Crédito Fundiário (INTERPA-PB) e em nível federal pelos Projetos de Assentamento de Reforma Agrária - PA's (INCRA/MDA, 2009).

No intervalo Sesmarias, Comunidades, Sítios, Assentamentos houve uma modificação significativa no que se refere ao acesso à terra. Entretanto, pelas constantes fragilidades denunciadas pelos aspectos negativos resultantes das estiagens $\mathrm{e}$ traduzidas em secas, denota-se que pouco avanço houve com relação à convivência com a semiaridez sempre presente na região. Uma das possíveis estratégias seria o cultivo de forragens xerófilas perenes ou não. Desta forma, a região passou por alguns ciclos voltados para esta estratégia como o da algaroba (Prosopis juliflora), do buffel (Cenchrus Ciliaris L.), e da palma forrageira (Opuntia fícus-indica) em forma de monocultura.

Todos os processos de implantação geraram danos ao ambiente pela substituição da vegetação de caatinga por estas monoculturas, com raríssimas exceções do consórcio algaroba $\mathrm{x}$ buffel. A monocultura atrelada à exploração excessiva dos solos sem reposição de nutrientes e com altíssima exportação destes por ocasião das colheitas e sem cuidados com as culturas instaladas consideradas como "rústicas", as colocou como de exploração marginal e, portanto, sem maiores interferências, exceto nos períodos secos dos anos e nas estiagens mais prolongadas quando do uso destas forragens.

Com a palma forrageira, notadamente a variedade Gigante (Opuntia fícus-indica), não foi diferente. Plantada como monocultura extremante adensada para "abafar" as plantas espontâneas e em áreas menos "nobres", revelou-se, mesmo nestas condições, como refrigério nos períodos secos, até o surgimento de problemas advindos da forma de condução: exploração do mesmo horizonte do solo por décadas; não reposição de nutrientes; pouco ou nenhum trato cultural; cortes sucessivos em épocas mais diferenciadas possíveis; manutenção da população por décadas gerando "matas de palmas"; nenhum controle de pragas e doenças.

Este cenário mostrou-se extremante positivo para o ataque destas e em especial da praga denominada de cochonilha-do-carmim (Dactylopius

opuntiae) que permaneceu presente na região por cerca de quinze anos. Esta praga atacou indistintamente desde os pequenos aos grandes proprietários, resultando na 
(SILVA et al., 2017)

erradicação da cultura da palma Gigante na região. Pode-se afirmar que a monocultura; o adensamento do cultivo; o pouco crédito ao uso de produtos naturais no controle; a ausência histórica de pulverizações em culturas "pouco nobres" como a palma e o "cruzar de braços" frente ao "desconhecido" contribuíram em muito para a disseminação da praga.

Pergunta-se então: como se encontra a produção da palma forrageira na região do cariri? Quais as influências de tal cultura na concepção sócio econômica dos sujeitos que a cultivam? Quais os desafios encontrados pelos agricultores no processo de produção e para manter o cultivo?

Dentro destes questionamentos, o principal objetivo desse trabalho foi o de analisar aspectos ligados aos fatores socioeconômicos voltados a produção da palma forrageira atrelada à convivência com o Semiárido Brasileiro - SAB, junto aos sujeitos no Assentamento Zé Marcolino que cultivam ou já cultivaram a palma forrageira. Neste recorte, optamos por interpretar como as relações se estabelecem a partir do cultivo de tal forrageira e como se encontraessa cultura frente as problemáticas que vem marcando sua produção, apontando assim os reflexos nos processos produtivos, principalmente na pecuária, a partir da fala de agricultores e alguns autores que embasam nossa discussão teórica.

\section{Pressupostos teórico-metodológicos}

Esta pesquisa faz parte de um recorte de um trabalho de dissertação, onde por meio do Estudo de Caso na pesquisa participante passamos a compreender as dinâmicas de camponeses e camponesas que cultivavam a palma forrageira (Opuntia fícus-indica) no Assentamento Zé Marcolino, localizado na cidade da Prata, Cariri da Paraíba.

A escolha do Assentamento Zé Marcolino ocorreu em função do mesmo estar inserido no território do Cariri Ocidental, onde uma das principais atividades econômicas é a pecuária. Como suporte forrageiro utilizado na dieta dos rebanhos, destacava-se o cultivo da palma forrageira, cactácea exótica introduzida nos sistemas de produção do Semiárido Brasileiro em função de sua rusticidade, palatabilidade, adaptação e características nutricionais.

Assim, a produção de palma se tornou uma boa estratégia de convivência com a Semiaridez, pois permitiu que o processo produtivo obedecesse a uma melhor lógica de sustentabilidade nas dimensões econômica, ambiental e social. Pereira (2008) verificou que no período Pré-Assentamento, a Fazenda apresentava 42,49 ha de palma plantados e que por ocasião do Assentamento este valor foi modificado para cerca de 28,38 ha.

Diante das vantagens da palma forrageira, nota-se a necessidade de estudos que esbocem aspectos socioeconômicos relacionados aos sujeitos que cultivam tal cultura na área estudada. A compreensão sociocultural que envolve o cultivo da palma está diretamente interligada à realidade de seca climática característica do clima local. O ano de 2012 foi marcado por chuvas abaixo da Norma Climatológica ${ }^{1}$, caracterizando uma grande estiagem/seca que tem se prolongado até o presente momento, dezembro de 2013.

A falta da base forrageira dos rebanhos, representada em especial pela palma dizimada pela cochonilha-do-carmim, exige $o$ aprofundamento sobre essa problemática das reservas alimentares, buscando respostas sobre o que se perdeu e o quanto era necessário para o atendimento das necessidades.

Diante de tais realidades, buscamos realizar uma abordagem que denominamos de caráter qualitativo. Consideramos como pesquisa qualitativa, a abordagem proposta por Günther (2006) afirmando que:

São características da pesquisa qualitativa sua grande flexibilidade e

\footnotetext{
${ }^{1}$ A organização Meteorológica Mundial (OMM) define Normais como "valores médios calculados para um período relativamente longo e uniforme, compreendendo no mínimo três décadas consecutivas" e padrões climatológicos normais como "médias de dados climatológicos calculadas para períodos consecutivos de 30 anos". Disponível em<http://www.inmet.gov.br/>
} 
(SILVA et al., 2017)

adaptabilidade. Ao invés de utilizar instrumentos e procedimentos padronizados, a pesquisa qualitativa considera cada problema objeto de uma pesquisa específica para a qual são necessários instrumentos e procedimentos específicos (p. 204).

Em diálogo com esse caráter, como ferramenta metodológica para coleta de dados e informações foram utilizadas entrevistas semiestruturadas dentro de uma abordagem participativa, onde o pesquisador se insere na dinâmica dos sujeitos da pesquisa, vivenciando os processos e se tornando parte deles. O verbo "participar" significa tomar parte de um processo e os indivíduos são sujeitos deste processo. É um princípio e uma conquista básica da democracia, que possibilita que as pessoas tenham uma intervenção ativa e importante em todas as decisões que influenciem suas vidas (KUMMER, 2007).

Desta forma, norteamos alguns horizontes que nos proporcionou atender os objetivos da pesquisa. Tecemos nosso caminho entre os desafios vivenciados a cada dia, mas que nos incentivaram a estar sempre em movimento, tal qual a rotina dos vários camponeses e camponesas.

\section{Resultados e discussões}

A palma é uma das plantas mais bem distribuídas e exploradas nas regiões áridas, colaborando nas atividades de agricultores que lidam principalmente com a pecuária de pequeno porte, sendo assim economicamente rentável sua produção (BARBERA, 2001). A palma forrageira Opuntia fícus-indica (L.) Mill. - cactácea exótica originária do México (HOFFMANN, 2001), está presente nos quatro continentes do mundo com diversas finalidades, com um maior destaque para sua utilização na alimentação animal.

Existem várias vertentes para as versões da chegada da palma no Brasil. Entretanto, a mais completa contribuição vem dos escritos de Octávio Domingues, em a Origem e Introdução da Palma Forrageira no
Nordeste, publicado em 1963. O autor elucidou que a palma forrageira foi introduzida no Brasil possivelmente durante a colonização, com intuito principal de extração do corante (carmim) da cochonilha (hemíptero produtor do corante), proveniente das ilhas Canárias, onde a criação da Cochonilha foi muito importante no século XVIII.

Entretanto, esta exploração não teve sucesso no Brasil. Assim, entrando em decadência, a palma passou a fazer parte dos jardins botânicos e praças, se disseminando como planta ornamental. Posteriormente, foi identificado seu potencial forrageiro para a alimentação animal, que data do começo do Século XX (DOMINGUES, 1963).

A palma forrageira foi introduzida no Nordeste depois de 1900, embora sua difusão na região aconteça somente após a seca de 1932, quando foram plantados do Piauí até a Bahia 222 campos de propagação de palma, intermediado pelo Ministério da Viação, pelo Dr. José Américo de Almeida, com a criação do serviço agroindustrial (DUQUE, 1973).

Em estudos realizados por volta de 1937, relata-se que existiam 284.455 hectares de palma, distribuídos da seguinte forma: 40,8\% no estado de Alagoas; Pernambuco detinha $33,4 \%$; na Paraíba $22,4 \%$ e os $3,4 \%$ restantes concentravam-se nos estados de Sergipe, Rio Grande do Norte e Ceará (DOMINGUES, 1963).

De acordo com Silva (2007) no Nordeste do Brasil são encontrados três tipos distintos de palma: a) gigante Opuntiaficus indica; b) redonda - (Opuntiasp) e miúda Nopaleacochenilifera. Em estudos realizados por Santos et al., (2006), observou-se que a área de palma Opuntia fícus indica (L.) Mill aumentou nos períodos de maior estiagem e que a forrageira possui em média $90,0 \%$ de água em sua composição, sendo de grande valia para o auxílio de líquido na alimentação animal.

A importância dessa forrageira é nítida no Assentamento Zé Marcolino, o que é comprovado através de expressões como: “ $E$ ' 
(SILVA et al., 2017)

um comerzão ${ }^{2}$ pra os bichos" ou "É raçãozona ${ }^{3}$ forte". A palma é pautada nas falas dos agricultores e agricultoras, como sendo a principal base para a alimentação dos animais, principalmente nesta época - 20112012 - em que eles atravessam um longo período de estiagem no Cariri e em outras regiões.

Santos et al., (2012), menciona que esta importância está ligada às suas características morfofisiológicas, por ser uma forragem que suporta longos períodos de estiagem, além de suprir o animal em suas necessidades de água, sendo um alimento rico em carboidratos-não-fibrosos, se tornando a principal fonte de energia para os ruminantes, embora seja necessária a sua associação com outros alimentos em função do seu baixo teor de fibras, pois "embora seja considerado um alimento volumoso, a palma apresenta baixos teores de fibra o que pode ser, em parte, responsável pelos distúrbios digestivos $\mathrm{e}$ pelos baixos teores de gordura no leite" (OLIVEIRA, 2011).

A palma é sempre servida aos animais em conjunto com outros alimentos, com o intuito de balancear a ração, pois de acordo com Santos et al., (2006) a palma, mesmo com seu valor nutritivo e de digestibilidade elevados, necessita ser complementada com volumosos como silagens, fenos, restos de cultura, bagaço de cana, pasto e capins para, além de satisfazer as exigências dos animais, principalmente leiteiros, evitar diarreias (não patológicas) que normalmente ocorrem quando os animais são alimentados exclusivamente com a palma.

Como o cultivo da palma na região vem sempre associado à produção de leite, estando presente como a principal base de produção econômica dos agricultores e agricultoras do Assentamento Zé Marcolino, a produção de leite é um dos fatores principais para a valorização dada a essa forrageira. Por muitas vezes escutamos deles e até mesmo das crianças, que os animais alimentados com a palma dobravam a produção de leite. Desta

\footnotetext{
${ }^{2}$ Termo regional para se referir à comida ou forragem de boa qualidade.

${ }^{3}$ Idem.
}

forma Oliveira (2011) recordou, que no "Nordeste brasileiro a palma é utilizada principalmente nas bacias leiteiras dos Estados de Pernambuco e Alagoas, mas também é encontrada nos Estados da Paraíba e Bahia".

Mesmo sendo notadamente importante nesses processos produtivos, hoje essa realidade de fornecimento da palma aos animais vem sofrendo algumas modificações, mediante o período prolongado de estiagem na região e ao ataque da cochonilha do carmim aos campos de palma.

Em meio a estes processos de escassez hídrica, uma das alternativas encontradas por um agricultor no Assentamento é o plantio adensado para a subsequente venda da forrageira, gerando assim o sustento da família, pois neste período vários agricultores precisam comprar alimentação para seus animais e como a palma é primordial nesse processo, o agricultor tem a venda garantida. Como por exemplo, Seu Demar, que tem três hectares de palma e dois de Capim Buffel (CenchrusCiliaris L.) no seu lote de 20,0 hectares. Ele enfatiza que é "porque a palma é boa, quem num tem tá vendo aí! Quem tem tá apurando dinheiro. A pessoa tem que plantar muita palma! Quanto mais, melhor, é uma ração que rende muito. É rendosa, palma e capim buffel'.

Dessa maneira, Seu Demar encontrou como tática o plantio para venda da palma nesta época, viabilizando assim o sustento de sua família e dos seus processos produtivos, já que o período é de carência de tal forrageira, como bem comenta Seu Neném Grosso, relacionando o aumento no preço da palma:

\footnotetext{
"Tem gente que tem mais uma coisinha e tá vendendo a 300 reais.Num é como antigamente que a gente chegava custava $R \$ 10,00-20,00$ por milheiro de palma comum, porque tinha a palma $e$ era mais fácil que hoje. Mas hoje num tem condições, mesmo se o cabra quiser numtem condições. Imagina aí a $R \$$ 300,00 um milheiro? E o pior que num tem não pra vender, a gente tem que comprar um e ir plantando, daqui a pouco já tem dois, e é dessa maneira".
} 
(SILVA et al., 2017)

A viabilidade econômica de redução da palma vem sendo drasticamente afetada por estas condições adversas que pontuamos, esse fato fica bem explícito na fala de seu Neném Grosso. A palma gigante já vinha sendo dizimada pela cochonilha-do-carmim (Dactylopiusopuntiae) na região desde 1998. Esta, que de acordo com Carvalho (2012), é originária do México e criada em vários países, com destaque para o Peru e outros países, para a produção do corante natural carmim de cochonilha, foi de grande importância comercial.

Carvalho (2012) afirmou que nunca houve nenhum registro desta praga entre os plantadores de palma do Nordeste até o final do século passado quando pesquisadores do IPA - Instituto de Pesquisas Agronômicas do Estado de Pernambuco trouxeram cochonilhas do México para a realização de pesquisas agronômicas no município de Sertânia - PE, originando assim sua disseminação e catástrofe que ora acontece em plantios de palma especialmente nos estados de Pernambuco, Paraíba e Rio Grande do Norte. Disseminou-se assim o inseto a partir dessa área experimental original para plantios próximos que foram rapidamente infestados e serviram de novos pontos de disseminação que ocorre principalmente pelo comércio de palmas e animais infestados com esses insetos, além do vento que pode transportar principalmente as formas jovens, conhecidas por ninfas migrantes.

No Assentamento Zé Marcolino essa realidade foi bem presente. De acordo com grande parte dos agricultores, a causa da destruição da palma foi através da cochonilha, não conseguindo assim reestruturar seus plantios, que se atrelando a seca atual ficou ainda mais difícil.

De acordo com relatos de Seu Robério, podemos identificar parte de sua experiência, quando o questionamos com relação aos problemas encontrados no plantio de palma:

"Era só a cochonilha né, aí depois a palma doce acabou-se o problema num pé. Aí veio outro pior que foi a seca que acabou com tudo, tá acabando com tudo, além de diminuir o rebanho todo, acabou com a palma todinha, hoje quem quiser palma, o povo tá produzindo ai só pra vender. A cochonilha ninguém acaba, pulverizei com detergente, água sanitária, sabão em pó.Mas é um custo alto. Lá no meu pai também tinha um pedaço lá, tinha a palma redonda lá. Ôche, pulverizava quando era no outro mês de novo, e quanto mais seca mais ela (a cochonilha) acha bom. No inverno ela se afasta chega fica pouquinha, quando bate o verão aí é que ela vem bonitinha. E o pior que ela 'voa', eu fui buscar uma caminhonete lá em Santa Luzia, elas chega tava aqueles papel, branca, branca. Aí peguei trouxe, era batendo lá no outro chega tava branco aquela névoa, ela voando. Eu acho que hoje aqui tem que passar muito tempo assim pra se dizer acabou-se a cochonilha, porque onde tem um pé de palma comum ela tá encostada. Ô bicha perigosa!".

Como Seu Robério bem enfatizou, a cochonilha iniciou um processo que a seca finalizou, a "destruição" da palma forrageira. Outro ponto abordado pelos agricultores é que corriqueiramente aparece na palma uma "lendja", que de antemão não acaba com a palma e não traz danos irreparáveis, mas é sempre uma constante nos palmais.

Essa "lendja" identificada por Seu Robério é denominada de cochonilha de escamas (Diaspisechinocacti Bouché), também popularmente conhecida como escama, piolho ou mofo da palma, sendo caracterizado como um inseto cosmopolita que ocorre em todas as regiões onde a cactácea é cultivada. A praga infesta às raquetes ou artículos com suas colônias, onde formam adultas, que são protegidas por uma escama ou escudo de cera, sugando a seiva para se alimentar, causando inicialmente um dano direto pela ação esfoliadora, quando as raquetes começam a apresentar clorose, em seguida causando um dano indireto, pois se trata de um inseto picador-sugador, que abrem os orifícios por onde penetram

\footnotetext{
${ }^{4}$ Corruptela de Lêndea.
} 
(SILVA et al., 2017)

microrganismos que causam o apodrecimento e queda das raquetes, consequentemente, a morte da planta (LOPES et al., 2012).

Uma das estratégias para essa "lendja", como é popularmente conhecida pelos agricultores do Assentamento Zé Marcolino, e que em sua totalidade foi enfatizada como ocorrência nos palmais, foi encontrada por Seu Sebastião, ao realizar uma experiência em seu cultivo, vejamos:

\begin{abstract}
"Olhe eu planto a palma porque sem palma ninguém cria. É palma e capim! Porque a palma veja só, ela é boa pra os animais pra tudo no mundo, agora essa aqui que tá dando a doença tá quase perdida. Agora se você tiver um pouco de atividade pra num deixar ela tomar de conta, você consegue, porque aqui mesmo eu tinha muita palma. Isso aqui mesmo era cheio, quando a 'doença' começou ela (a palma) játava com uns dois pra três anos. Já grande! Aí num tinha remédio, batia pra um lado batia pra o outro ninguém tinha, todo mundo perdendo as palma. Mas só que eu fiz um 'remédio' aqui mesmo e consegui matar aquela lendja da palma. Eu tirei um fecho da maniçoba e um fecho da carrapateira verde com semente com tudo ali no rio. Aí, trouxe pra casa, cortei na forrageira bem fininha coloquei dentro de um tambor d'água de 20 litros, junto coloquei $1 \mathrm{~kg}$ de sal, mexi e deixei aqui. Aí, passou a noite, o dia e a noite do outro dia, duas noites e um dia. Aí, no outro dia eu peguei esfreguei, esfreguei e coei, coloquei na máquina (pulverizador) e pulverizei. Quando foi com três dias eu fui lá e num tinha nenhuma lendja mais. Mais nenhuma lendja na palma!”.
\end{abstract}

Seu Sebastião tem uma sensibilidade enorme com a natureza, com as plantas e os bichos. Ele respeita os limites naturais do ambiente e aprendeu muito bem como lidar com ele. Foi ensinado pela vida a como observar e modificar os espaços, respeitando seus limites e suas diversidades, é um exemplo de educador. Assim, ele encontrou em suas aprendizagens, a medida que testava

\footnotetext{
5 Termo regional para designar ataques de pragas e doenças de plantas.
}

e buscava soluções para melhorar seus processos no campo, tendo assim sua experiência como exemplo para outros agricultores que têm os mesmos problemas com a palma e consequentemente a falta de alimentação para os animais, causando posteriormente déficits nos processos produtivos e econômicos.

De acordo com Bruno, filho de um dos assentados (as), os animais quando alimentados com palma aumentam consideravelmente a produção de leite, vejamos um pequeno trecho da fala de Bruno:

“Tem diferença demais! No dia que elas
comem palma no outro dia elas
agradecem, no outro dia compensa o que
comeu, mas quando não come, pra
criação, quer saber no outro dia quando
vai tirar o leite. Olhe, você tira 10 litros
sem dar à palma. No outro dia tira 13,
14,15 litros comendo a palma, ou
quando solta no pasto verde, chega
amanhece com os peito cheios...".

Santos et al., (2005), corroboraram com a fala de Bruno, abordando que as Opuntias e Napaleas mesmos pobres em proteína possuem uma alta produção de matéria seca digestível, sendo altamente palatável pelos ruminantes, melhorando substancialmente o valor nutritivo da dieta, ainda mais se associada às forrageiras nativas ricas em proteínas e leguminosas. Seu Neném Grosso também abordou a importância e relata a aflição pela falta da forrageira para os animais:

\footnotetext{
“As vacas 'produz' mais leite. É o seguinte quando todo mundo tinha palma aquitodo mundo tinha condição de criar, se eu tivesse palma tava com oito ou dez cabeças de gado, mas sem palma aqui quase ninguém tem mais bicho porque num tem o que dá. Comprar comida o cabra num pode...".
}

É nas falas dos agricultores que identificamos as principais angústias pela falta da alimentação para os animais, principalmente esta que vem sendo 
(SILVA et al., 2017)

recorrentemente repetida nas falas, a palma forrageira.

De acordo com Oliveira et al., (2010) a palma aparece neste contexto como uma alternativa de cultivo altamente adaptada ao clima semiárido, visto ser uma cultura com mecanismo fisiológico especial no que se refere à absorção, aproveitamento e perda de água, que são características impares para estas regiões, aí estão suas cruciais importâncias, atuando como reserva forrageira, é um pilar significativo na sustentabilidade da pecuária regional, segmento que vem sendo fortemente atingido pela escassez de alimentos.

Vale salientar que a palma aparece na maioria das falas como a base para a alimentação dos animais, sendo complementada posteriormente com outros alimentos que balanceiam a ração. Desta forma, foi possível identificar que a falta da palma, seja originada pela deficiência hídrica ou pelas pragas e/ou doenças que a atinge, denota perda substancial nos processos dos vários agricultores da região Semiárida, principalmente do Cariri paraibano, este que tem uma forte característica de aptidão para pecuária, como abordamos no decorrer de nosso trabalho. É neste sentido, pela importância crucial de tal forrageira para os agricultores, que pautamos um viés dentro de nosso trabalho, que foi estabelecido pela relação que a palma vem promovendo para uma melhor convivência na região Semiárida, seja nos processos produtivos, seja nas relações educacionais, escolares e não escolares.

\section{Reflexões Finais}

A seca enquanto processo antigo vem assolando inúmeras famílias do Semiárido Brasileiro desde muito tempo, causando debilidade econômica, social e cultural na sociedade. Esse processo vem atrelado às políticas assistencialistas desde a sua existência. Estas amenizam momentaneamente alguns dos déficits nos quais se encontram tais sujeitos. Além das políticas, ações de cunho governamental também se firmaram desde muito tempo para potencializar a região das secas, como assim era chamada.

Frente a este assistencialismo, vem o despreparo para conviver nas regiões com deficiência hídrica elevada, assim condiciona à perda dos cultivos, com destaque para o da palma forrageira, que como foi possível identificar, apenas um dos agricultores da pesquisa manteve seu palmal. Ademais, isto traz consequências como as perdas dos rebanhos e da base forrageira representada preponderantemente pela palma forrageira sendo aniquilada pela praga da cochonilhado-carmim. A palma é considerada para estes agricultores a base para alimentação de seus animais, sendo complementada com outros alimentos como ramas e tortas. Foi possível identificar que o sucesso da forrageira não está em apenas "alimentar" os animais, mas também nos seus valores de porte nutritivo ou econômico.

Os camponeses destacam sua importância quanto ao aumento na produtividade dos animais (leite e carne), sendo a forrageira peça chave nesse processo. Sua importância também vem atrelada à base econômica de alguns agricultores nos períodos de estiagem, pois a forrageira adquiriu valor econômico significativamente superior nos últimos anos. Entretanto, mediante este aumento e debilidade de produção, a palma tem se tornado um bem escasso, sendo dizimada pela cochonilha e posteriormente abolida sua produção em função da seca, restando assim poucos campos de palma.

Mediante os resultados, identificamos que se faz necessário que trabalhos voltados para o fortalecimento da cultura da palma forrageira sejam mais pontuais em função de tal cultura vir atrelada a um dos principais, para não dizer o principal suporte forrageiro da região, influenciando nos processos socioeconômicos destes camponeses. Que estratégias de convivência com a região semiárida a partir do cultivo de plantas mais adaptadas ao clima sejam trabalhadas em estudos posteriores, vislumbrando outras 
(SILVA et al., 2017)

culturas, tratos e manejos sustentáveis nos processos produtivos, para que assim, possamos teoricamente dar respaldo a estas estratégias.

\section{Agradecimentos}

Aos camponeses e camponesas do Assentamento Zé Marcolino, as educadoras e crianças da Escola Plínio Lemos - Escola da Terra -; e a meus orientadores, gratidão!

\section{Referências Bibliográficas}

BARBERA， G. História e importância econômica e agroecológica. In: FAO. Agroecologia, cultivo e usos da Palma Forrageira. Versão em língua Inglesa, 1995, SEBRAE/PB, 2001, versão em língua Portuguesa. p: 1-9.

CARVALHO, R. A.; LOPES, E. B.; SILVA, A. C.; LEANDRO, R. S.; CAMPOS, V. B. Controle alternativo da cochonilha-do-carmim em palma forrageira no cariri paraibano. 2012. Disponível em: http://www2.mma.gov.br/sitio/ Acesso em: 12 de agosto de 2013.

DOMINGUES, O. Origem e Introdução da Palma Forrageira no Nordeste. Recife. Instituto Nabuco de Pesquisas Sociais, 1963. $75 \mathrm{p}$.

DUQUE, J. G. O Nordeste e as lavouras xerófilas. 2 ed. Mossoró: Escola Superior de Agricultura de Mossoró / Fundação Guimarães Duque (Coleção Mossoroense, v. CXLIII), 1973. 316p.

DUQUE, J. G. Solo e água no polígono das secas. 5 ed. Mossoró: Escola Superior de Agricultura de Mossoró / Fundação Guimarães Duque (Coleção Mossoroense, v. CXLII), 1980. 273p.

GÜNTHER, H. Pesquisa Qualitativa Versus Pesquisa Quantitativa: Esta É a Questão? Psicologia: Teoria e Pesquisa, Brasília, v. 22 n. 2, p: 201-210, 2006.
HOFFMANN, W. Etnobotânica. In: Agroecologia, cultivo e usos da palma forrageira. Traduzido por SEBRAE/PB. João Pessoa: SEBRAE/PB, 2001. p.12-19.

KUMMER, L. Metodologia Participativa no meio rural: uma visão interdisciplinar conceitos, ferramentas e vivências. Salvador, GTZ - Agência Alemã de Cooperação Técnica, 2007. 155p.

LOPES, E. B.; BATISTA, J. de L.; BRITO, C. H. de; SANTOS, D. C. dos. Pragas da palma forrageira. In: LOPES, E. B. Palma Forrageira: cultivo, uso atual e perspectivas de utilização no Semiárido nordestino. 1 ed. João Pessoa: EMEPA-PB, 2012. p: 61-78.

OLIVEIRA, A. S. C.; CAVALCANTE FILHO, F. N.; RANGEL, A. H. do N.; LOPES, K. B. de P.A palma forrageira: alternativa para o Semi-árido. Revista Verde, Mossoró, v.6, n.3, p: 49 - 58, 2011.

OLIVEIRA, F. T. de; SOUTO, J. S.; SILVA, R. P. da; ANDRADE FILHO, F. C. de; PEREIRA JÚNIOR, E. B. Palma forrageira: adaptação e importância para os ecossistemas áridos e semiáridos. Revista Verde, Mossoró, v.5, n.4, p: 27-37, 2010.

PEREIRA, D. D. Cariris paraibanos: do sesmarialismo aos assentamentos de reforma agrária. Raízes da desertificação? 2008. (Tese de Doutorado) - Universidade Federal de Campina Grande - UFCG, Campina Grande - PB, 341p.

SANTOS, D. C. dos; ARAÚJO, L. de F.; LOPES, E. B.; VASCONCELOS, M. F. de. Usos e aplicações da palma forrageira. In: LOPES, E. B. Palma Forrageira: cultivo, uso atual e perspectivas de utilização no Semiárido nordestino. 1 ed. João Pessoa: EMEPA-PB, 2012. p: 99-150.

SANTOS, D. C. dos; FARIAS, I.; LIRA, M. de A.; SANTOS, M. V. F. dos; ARRUDA, G. P. de; COELHO, R. S. B.; DIAS, F. M.; MELO, J. N. de. Manejo e utilização da palma forrageira (Opuntia e Nopalea) em 
(SILVA et al., 2017)

Pernambuco. Recife: $\quad$ Empresa conhecimento atual e novas perspectivas de Pernambucana de Pesquisa Agropecuária - uso. Recife: Ed. Universitária da UFPE, 2005, IPA, 2006. 48p. p: 143-162.

SANTOS, M. V. F.; FERREIRA, M. A.; BATISTA, A. M. V. Valor nutritivo e utilização da palma forrageira na alimentação de ruminantes. In: MENEZES, R. S. C.; SIMÕES, D. A.; SAMPAIO, E. V. S. B. A palma no Nordeste do Brasil:

SILVA, R. M. A. da. Entre o Combate à Seca e a Convivência com o Semi-Árido: políticas públicas e transição paradigmática. Revista Econômica do Nordeste, Fortaleza, v. 38, n. 3, p: 466-485, 2007. 